\title{
Papillary lesions of the breast: a review
}

\author{
Denny Lara Nuñez*1, Fernando Candanedo González², Mónica Chapa \\ Ibargüengoitia1, Rosaura Eugenia Fuentes Corona1, Antonio Carlos Hernández \\ Villegas ${ }^{1}$, Mariana Licano Zubiate ${ }^{1}$, Sara Eugenia Vázquez Manjarrez ${ }^{1}$ \& Carlos Casian \\ Ruiz Velasco ${ }^{1}$ \\ ${ }^{1}$ Department of Radiology, Instituto Nacional de Ciencias Médicas y Nutrición Salvador Zubirán, Mexico City, Mexico \\ 2 Department of Pathology, Instituto Nacional de Ciencias Médicas y Nutrición Salvador Zubirán, Mexico City, Mexico \\ *Author for correspondence: dennylaran5@gmail.com
}

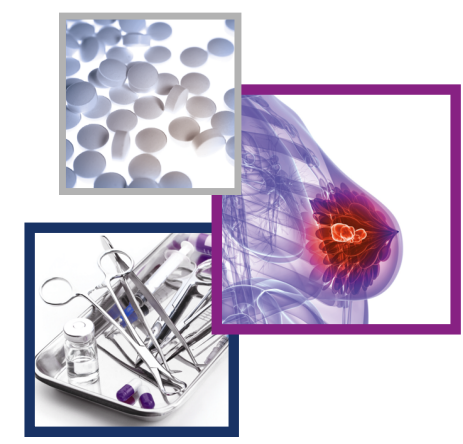

Papillary breast lesions are rare breast tumors that comprise a broad spectrum of diseases. Pathologically they present as mass-like projections attached to the wall of the ducts, supported by fibrovascular stalks lined by epithelial cells. On mammogram they appear as masses that can be associated with microcalcifications. Ultrasound is the most used imaging modality. On ultrasound papillary lesions appear as homogeneous solid lesions or complex intracystic lesions. A nonparallel orientation, an echogenic halo or posterior acoustic enhancement associated with microcalcifications are highly suggestive of malignancy. MRI has proven to be useful to establish the extent of the lesion. Core needle biopsy is the gold standard for diagnosis. Surgical excision is usually recommended, although treatment for papillomas without atypia is still controversial.

First draft submitted: 3 June 2020; Accepted for publication: 17 August 2020; Published online: 28 September 2020

Keywords: atypical papilloma $\bullet$ breast cancer $\bullet$ encapsulated carcinoma $\bullet$ invasive papillary carcinoma $\bullet$ papillary $\bullet$ papillary DCIS • solid papillar

Papillary breast lesions (PBLs) [1] account for less than 3\% of breast tumors and encompass a broad spectrum of proliferative diseases [2,3]. They represent less than $10 \%$ of benign lesions and less than $2 \%$ of all breast cancers [4]. Most of PBLs are benign although a small percentage can show atypical behavior or malignant characteristics. These lesions are exclusively intraductal neoplasms, although some cases of invasive carcinoma may have papillary architecture [5]. These lesions constitute a diagnostic challenge due to their broad spectrum of clinical, imaging and histologic characteristics [5]. Common symptoms include palpable masses and nipple discharge, although it is not uncommon for papillary lesions to be diagnosed in asymptomatic women or on screening [6].

Papillary lesions can be both benign and malignant and they comprise a variety of lesions including intraductal papilloma (IDP), IDP with atypia or ductal carcinoma in situ (DCIS), papillary DCIS, solid papillary carcinoma (SPC), encapsulated papillary carcinoma (EPC) and invasive carcinomas, including invasive papillary carcinoma (IPC) and invasive micropapillary carcinoma (IMPC) [7].

PBLs can also be classified by location (large or small ducts), nature of proliferating epithelial cells (hyperplastic, neoplastic or mixed lesions), presence of and location of myoepithelial cells and morphology (Figure 1) [8].

Benign intraductal papillomas are the most common PBLs and are also called central or solitary papillomas [8]. Differentiation between benign and malignant lesions is of utmost importance for diagnosis and management, particularly considering there is evidence that atypical ductal hyperplasia [9] and DCIS are associated with papillary lesions $[10,11]$. IPC and IMPC are very rare and not well documented. Malignant lesions are usually low nuclear grade and most are thought to behave in an in situ manner [8,12].

Mammographically, lesions can appear as masses of different sizes that may or may not be associated with microcalcifications. Sonographically, PBL can present as homogeneous solid lesions or complex intracystic lesions, although appearance varies with size. Ultrasound is helpful for evaluating the masses and providing information regarding the associated ducts [13] (Figure 2). Although we cannot fully rely on imaging features to make a final diagnosis, they can help to guide us toward appropriate management [14]. Mammography has a sensitivity and specificity of $78 \%$ by itself and these increase to $91 \%$ when ultrasound is also performed [4].

Future Medicine 


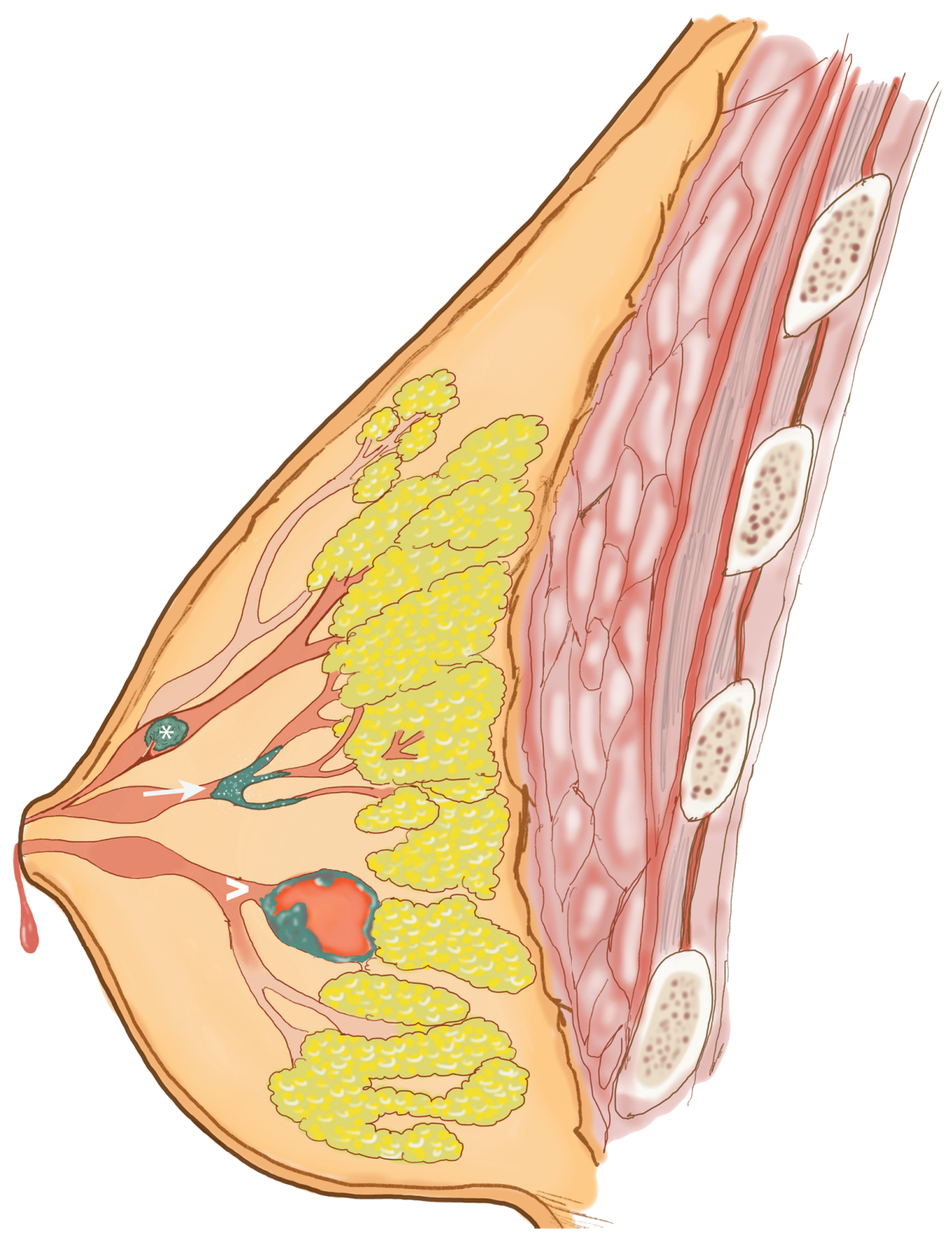

Figure 1. The appearance of different papillary lesions. The upper lesion demonstrates a solitary intraductal papilloma (asterisk) attached to the inner mammary duct wall by a fibrovascular core. The middle lesion (arrow) demonstrates micropapillary DCIS which is a variant growing around internal lining of a duct space with papillary projections and microcalcifications. The bottom lesion (arrowhead) represents a complex mixed cystic and solid mass, which tends to bleed centrally.

DCIS: Ductal carcinoma in situ.

MRI has proven superior for visualization of DCIS but published data for detecting intraductal lesions is still limited [13]. Papillomas may appear as masses with heterogeneous or homogeneous enhancement which can have intraductal components [15].

Pathologically PBL are described as mass like projections that are attached to the wall of the ducts and have a fibrovascular stalk lined by epithelial cells. The analysis of these lesions starts with the evaluation of three main characteristics: geometric characteristics of the fronds, quality and amount of stroma and characteristics of the epithelium [16]. The lesion's size can range from 5 to $20 \mathrm{~mm}$. PBLs can present as single or multiple and are commonly found in a central position of the gland, although they can be larger and peripherally located [2].

Image-guided core needle biopsy is the gold standard for diagnosis. However, for this particular pathology, percutaneous biopsy can be quite challenging due to the broad spectrum of histological findings and the subtle 
Figure 2. Benign papillomas. (A) Sagittal grayscale ultrasound shows a retroareolar oval, parallel, isoechoic mass in a dilated duct (arrow) (B \& C) Sagittal and transverse color Doppler ultrasound demonstrates a different case with an oval, parallel, circumscribed, isoecoic lesion with absent vascularity (arrow and asterisk). (D) Sagittal grayscale ultrasound of the same patient shows a dilated duct associated with a papillary lesion (arrow).

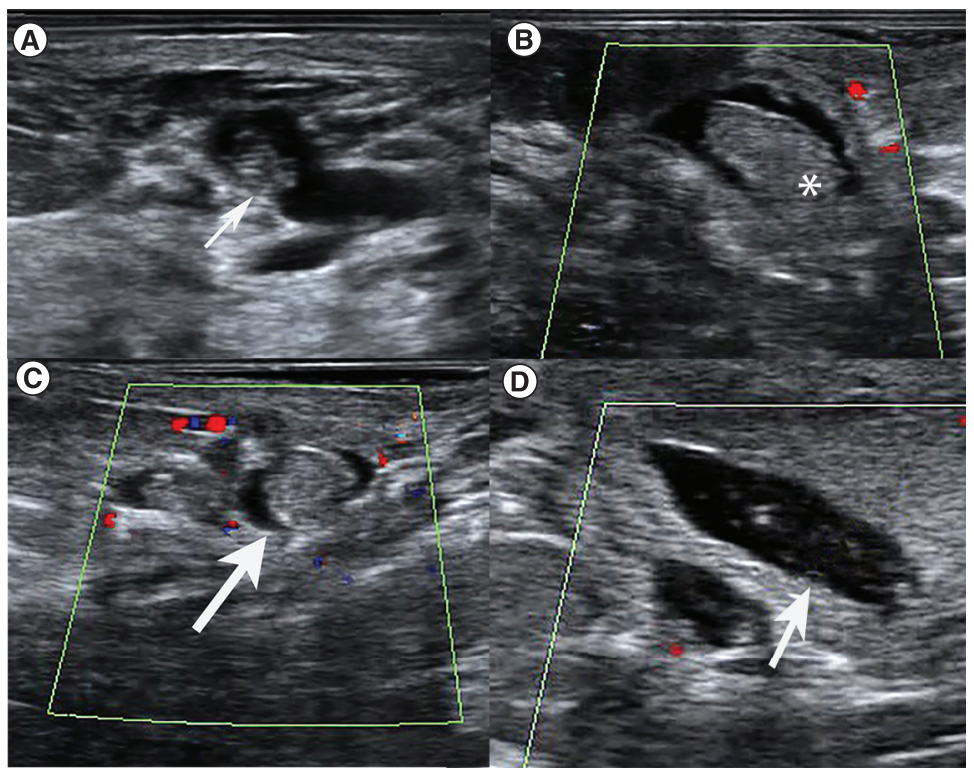

Table 1. Papillary breast lesion classification.

\section{Benign papillary lesion}

1. Intraductal papilloma (solitary)

2. Intraductal papillomatosis

Atypical papillary lesions

1. Intraductal papilloma with atypical hyperplasia

2. Papilloma with DCIS

Malignant papillary lesions

Noninvasive:

Invasive:

Invasive

1. Papillary ductal carcinoma in situ

2. Encapsulated papillary carcinoma

1. Invasive papillary carcinoma

3. Solid papillary carcinoma

2. Invasive micropapillary carcinoma

DCIS: Ductal

carcinoma in situ.

differences that exemplify each category [1]. Some advantages of percutaneous biopsy are avoiding unnecessary surgeries and knowing the preoperative diagnosis for surgical planning. On the other hand, underestimation of malignant lesions and an incomplete resection of the lesion has to be taken in consideration when choosing this method [17].

Surgical excision is recommended for papillary lesions following an image-guided core needle biopsy, specially to rule out malignancy when atypia is diagnosed. Treatment for papillomas without atypia is controversial and no agreement has been reached $[17,18]$.

Even though understanding clinical and pathological characteristics of breast lesions is necessary for an accurate diagnosis, imaging characteristics help orientate diagnosis for an optimal management. The classification used in this article (Table 1) of PBLs has been described for pathological findings; however, it has not been used to characterize papillary lesions at an imaging level in detail. Jagmohan $e t$ al. published a review of imaging features of PBLs as well as histologic characteristics. Eiada et al. [19] and Bloom et al. [4] published a review of papillary breast lesions, however pathology was not included and imaging characteristics were described in general for benign and malignant lesions without making a distinction between papillary carcinoma subtypes. Brooks et al. [2] described the commonest appearances on various imaging modalities for papillary lesions; however, a more detailed pathologic description is provided in this article, as well imaging characteristics for each type of papillary carcinoma which were not fully described. Basavaiah et al. [7], Rakha et al. [7], Tse el al. and Wei et al. [5] provided a full analysis of histopathological findings and updated concepts in diagnosis and classification of papillary lesions by categorizing them in benign, atypical and malignant; however, no radiologic findings are included in these articles. The aim of 


\begin{tabular}{|c|c|c|c|c|}
\hline PBL & $\begin{array}{l}\text { Nature of proliferating } \\
\text { epithelial cells }\end{array}$ & Imaging clues & $\begin{array}{l}\text { Prognosis and } \\
\text { aggressiveness }\end{array}$ & Pathology tips \\
\hline Benign papillomas & Hyperplastic & $\begin{array}{l}\text { Central lesions with round or oval } \\
\text { shape and circumscribed margins } \\
\text { associated to dilated ducts }\end{array}$ & $\begin{array}{l}\text { Potential of } 0-16 \% \text { for } \\
\text { malignant transformation }\end{array}$ & $\begin{array}{l}\text { - Present myoepithelial cells in papillae and } \\
\text { periphery } \\
\text { - Intraductal proliferation of epithelial and } \\
\text { myoepithelial cells within fibrovascular stalks } \\
\text { giving a frond-like appearance }\end{array}$ \\
\hline $\begin{array}{l}\text { Atypical papillary } \\
\text { lesions }\end{array}$ & $\begin{array}{l}\text { Mix of hyperplastic and } \\
\text { neoplastic }\end{array}$ & $\begin{array}{l}\text { - Similar to benign papillomas } \\
\text { - Circumscribed masses or } \\
\text { clusters of calcifications }\end{array}$ & $\begin{array}{l}\text { High risk of carcinoma } \\
(25-30 \%)\end{array}$ & $\begin{array}{l}\text { - Few or no myoepithelial cells } \\
\text { - Papilloma with ADH: area of atypia is }<3 \mathrm{~mm} \\
\text { - Intraductal papilloma with DCIS: area of } \\
\text { atypia es }>3 \mathrm{~mm}\end{array}$ \\
\hline $\begin{array}{l}\text { Papillary ductal } \\
\text { carcinoma in situ }\end{array}$ & Neoplastic & $\begin{array}{l}\text { - Peripherally located } \\
\text { - Multicentric disease }\end{array}$ & $\begin{array}{l}\text { - Associated with } \\
\text { extensive disease. } \\
\text { - Low risk of invasion }\end{array}$ & $\begin{array}{l}\text { - Coexists with other variants of DCIS } \\
\text { - Absent myoepithelial cells in the papillae but } \\
\text { surrounded by a peripheral layer } \\
\text { - Dilated ducts with protuberances that form } \\
\text { arches }\end{array}$ \\
\hline $\begin{array}{l}\text { Encapsulated } \\
\text { papillary carcinoma }\end{array}$ & -Neoplastic & $\begin{array}{l}\text { - Solitary, centrally located } \\
\text { - Typically well defined cystic } \\
\text { mass }\end{array}$ & $\begin{array}{l}\text { - High risk of local } \\
\text { recurrence } \\
\text { - Low risk of invasion }\end{array}$ & $\begin{array}{l}\text { - Absent myoepithelial cells in the papillae } \\
\text { and frequently absent in the periphery } \\
\text { - Rounded tumor and thick fibrous capsule } \\
\text { - Positive for estrogen and progesterone } \\
\text { receptors and negative for HER2 }\end{array}$ \\
\hline $\begin{array}{l}\text { Solid papillary } \\
\text { carcinoma }\end{array}$ & Neoplastic & $\begin{array}{l}\text { - } 95 \% \text { are unilateral } \\
\text { - Typically solid } \\
\text { - Central round well defined } \\
\text { nodules } \\
\text { - Often multinodular involving } \\
\text { peripheral areas }\end{array}$ & $\begin{array}{l}\text { - Metastases are rare } \\
\text { - Good prognosis } \\
\text { - Low risk of invasion }\end{array}$ & $\begin{array}{l}\text { - Absent myoepithelial cells in the papillae } \\
\text { and frequently absent in the periphery } \\
\text { - Well circumscribed, soft masses with positive } \\
\text { hormone receptors and negative for HER2 } \\
\text { - Low proliferation index } \\
\text { - Cells frequently show neuroendocrine and } \\
\text { mucinous differentiation } \\
\text { - Spindle cell morphology }\end{array}$ \\
\hline $\begin{array}{l}\text { Invasive } \\
\text { micropapillary } \\
\text { carcinoma }\end{array}$ & Neoplastic & $\begin{array}{l}\text { - Associated with high rate of } \\
\text { lymph node metastases } \\
\text { - High density masses with } \\
\text { spiculated margins }\end{array}$ & Aggressive form & $\begin{array}{l}\text { - Absent myoepithelial cells in the papillae } \\
\text { and periphery } \\
\text { - Morula-like epithelial group of cells } \\
\text { WITHOUT fibrovascular cores floating in } \\
\text { mucinous material. }\end{array}$ \\
\hline $\begin{array}{l}\text { Invasive papillary } \\
\text { carcinoma }\end{array}$ & Neoplastic & $\begin{array}{l}\text { Round oval circumscribed masses } \\
\text { with no metastatic disease }\end{array}$ & Good prognosis & $\begin{array}{l}\text { - Absent myoepithelial cells in the papillae } \\
\text { and periphery } \\
\text { - Papillary morphology in }>90 \% \text { of the } \\
\text { invasive tumor } \\
\text { - Papillae with fibrovascular cores. }\end{array}$ \\
\hline
\end{tabular}

this article is to synthesize the classification of PBLs, discuss molecular biology, treatment strategies, and highlight multimodality imaging findings as well as histologic characteristics for each type of PBL, including subtypes of papillary carcinoma. We provide a series of key imaging findings that present more frequently in all subtypes of PBLs to make diagnosis easier and more accurate. A brief summary is provided in Table 2.

\section{Biopsy techniques}

Once imaging findings are reported, histologic diagnosis is needed in order to dictate appropriate management. The percutaneous methods of choice are core-needle biopsy (CNB) and vacuum-assisted biopsy (VAB). Each one has advantages and disadvantages but present lower complication rates and shorter recovery times when compared with open excisional biopsy [20]. Main advantages for each biopsy technique are referred in Figure 3. Both CNB and $\mathrm{VAB}$ have a very high diagnostic accuracy, with a sensitivity, specificity, positive predictive value and negative predictive value of $94 \%$ or higher [20].

Regarding upgrade histologic rates from percutaneous biopsy compared with excised diagnosis, it has been reported that $\mathrm{CNB}$ has $0 \%$ upgrade rate for benign papilloma, 30\% for papilloma with ADH and $25 \%$ for papilloma with DCIS, resulting in an overall upgrade rate of $11.1 \%$ [21]. As for VAB, upgrade rate is of $0 \%$ for benign papillomas and $18.2 \%$ for atypical papillomas [22].

\section{Benign papillary lesions}

Benign papillary lesions can be divided into solitary and multiple types. They account for $70-85 \%$ of all PBL diagnosed by core needle biopsy [21]. Solitary papillomas occur most frequently in women between 35-55 years of 


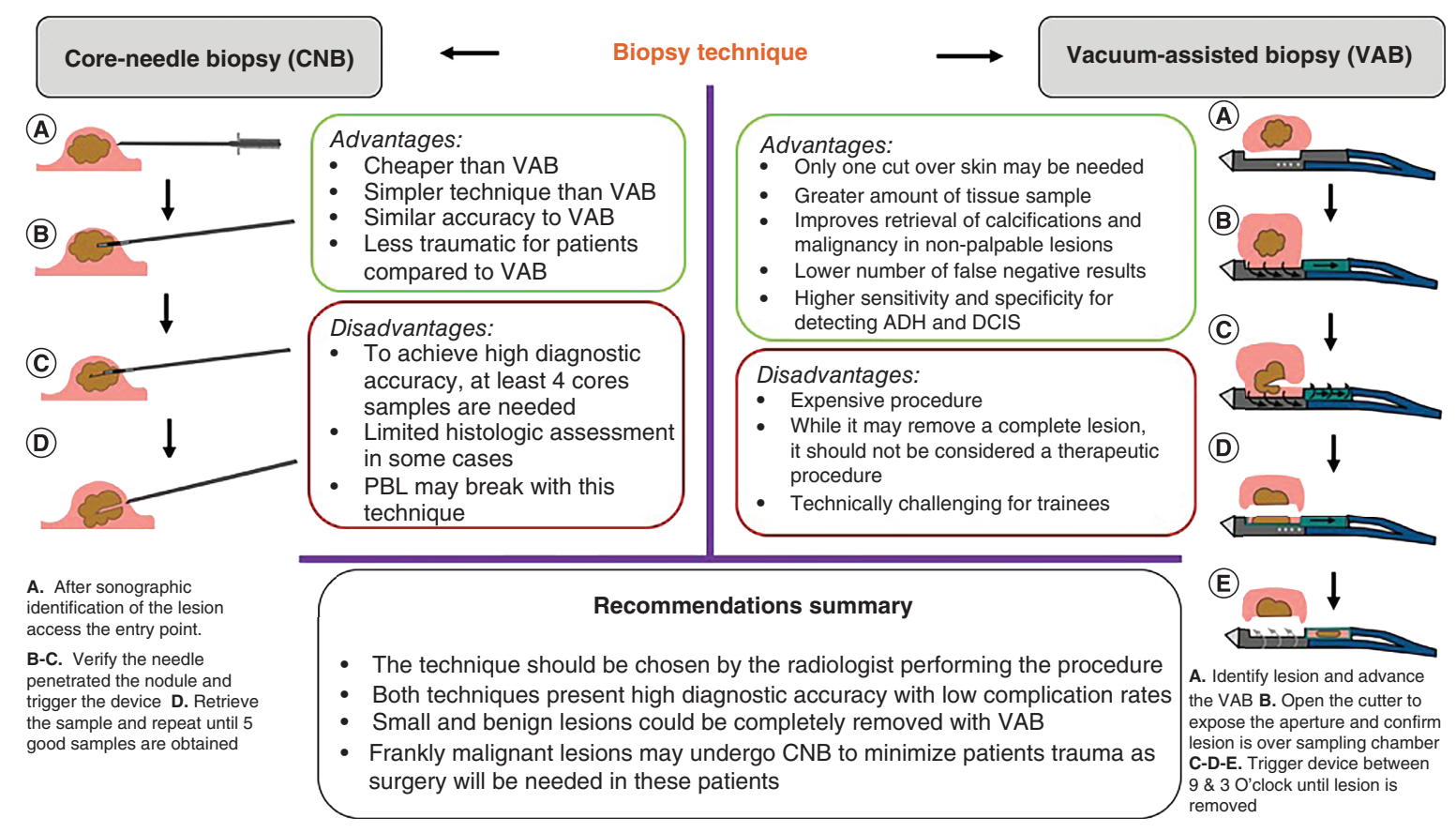

Figure 3. Bopsy techniques. Advantages and disadvantages of percutaneous biopsies.

ADH: Atypical ductal hyperplasia; CNB: Core-needle biopsy; DCIS: Ductal carcinoma in situ; PBL: Papillary breast lesions; VAB: Vacuum-assisted biopsy.

Figure 4. Benign papilloma. (A)

Hematoxylin-eosin, original magnification $\times 100$ shows an intraductal proliferation of epithelial and myoepithelial cells (arrowhead).

(B) Hematoxylin-eosin, original magnification $\times 200$ of multiple papillomas. Papillary lesion in a dilated duct (arrowhead). (C) Same case under high magnification $(\times 400)$ shows epithelial and myoepithelial cells without atypia (arrowheads).

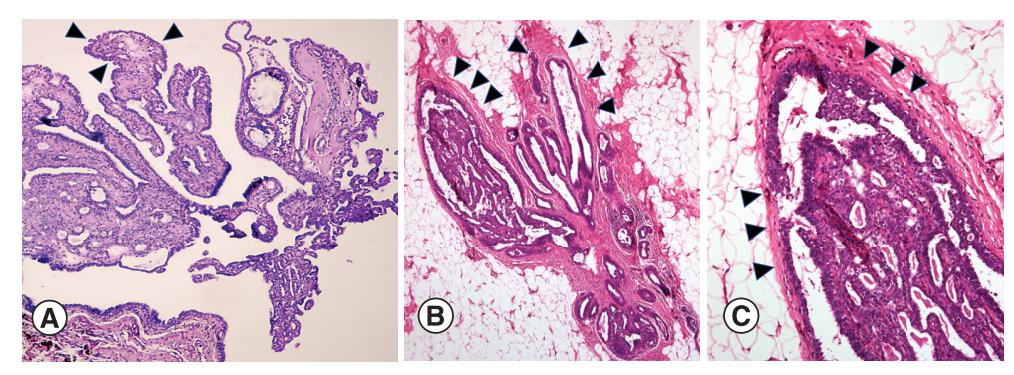

age and they are the most common cause of nipple discharge that can be either bloody or clear [4]. These lesions measure 2-3 mm and they are usually located centrally within the subareolar ducts [19,23].

Papillomatosis is defined when five or more papillomas are present. This occurs in $10 \%$ of the cases of intraductal papillomas and papillomatosis is frequently associated with DCIS and atypia [24]. Multiple papillomas frequently present as peripherally located lesions in distal and smaller ducts and can be bilateral [25]. These papillomas affect younger patients and clinically nipple discharge is not frequent. They present as palpable masses or are found in routine breast studies of asymptomatic patients [4,26]. Even when recurrence is more common in multiple papillomas, prognosis remains excellent [24].

Pathologically benign PBLs are defined by an intraductal proliferation of epithelial and myoepithelial cells within fibrovascular stalks giving a frond-like appearance (Figure 4). When either of these layers of epithelial or myoepithelial cells proliferate, the structure of the epithelium will be changed. Under low magnification a papilloma is seen as a compact mass of fronds with polygonal shapes and blunt morphology [16,27]. Myoepithelial cells are located between epithelial cells and the basement membrane and are covered by a luminal cell layer. Often these cells look inconspicuous, but frequently they can be seen clearly and even prominently. Epithelial cells frequently are seen as conventional ductal cells and often can have apocrine changes. The ducts in which papillomas proliferate can be occupied by eosinophilic secretions. For pathologists it can be challenging to differentiate mitotic figures in papillomas. The fronds of these lesions contain a high amount of collagen, fibroblasts and blood vessels. It is 


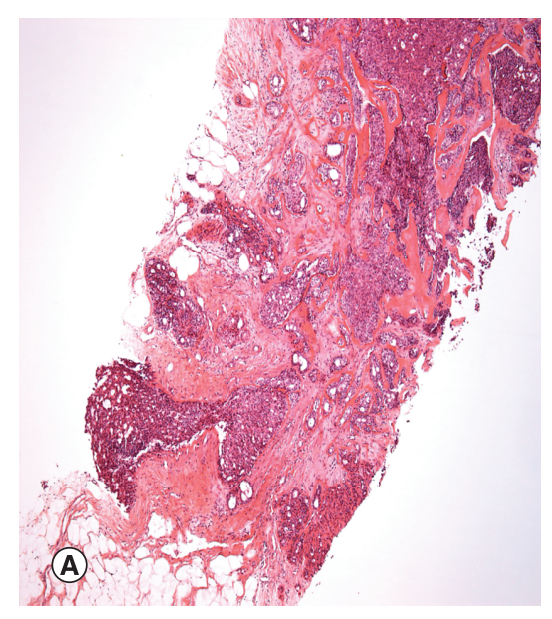

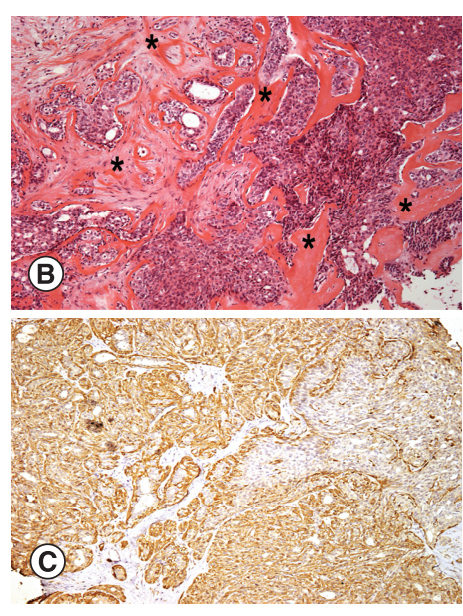

Figure 5. Sclerosing papilloma. (A \& B) Hematoxylin-eosin, original magnification $\times 100$ and $\times 400$. Core needle biopsy shows sclerosing areas and tubules located centrally (asterisk). (C) Immunohistochemistry, original magnification $\times 400$, shows calponin positive cells demonstrating myoepithelial cells.

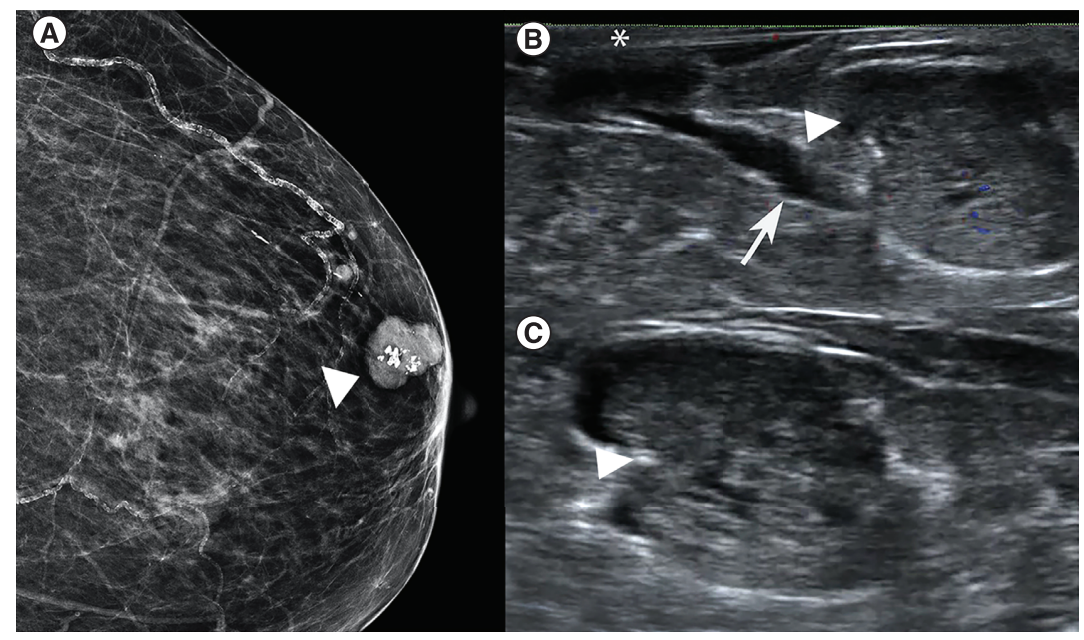

Figure 6. Benign papilloma. (A) CC view of the left breast shows a round circumscribed hyperdense retroareolar mass with coarse calcifications (arrowhead) (B \& C) Sagittal and transverse grayscale ultrasound demonstrates an oval, nonparallel circumscribed, heterogeneous mass (arrowheads). Note the proximity to the nipple (*) and the dilated duct from the nipple to the mass (arrow). CC: Craniocaudal.

important to note that papillomas contain a high amount of collagen whereas carcinomas contain a much lower proportion. Apocrine, squamous, mucinous and clear cell metaplasia are often seen in papillomas. Proportions of stroma and glands can vary in these lesions as well as stromal characteristics.

When a papilloma is chronic, the stroma undergoes hyalinization, fibroblasts disappear and capillary dilatation is seen [16]. Papillomas can develop calcifications, which is not common, but when they do develop, these form in stromal locations. These lesions are called sclerosing papillomas (Figure 5) and they remain benign lesions due to the fact that myoepithelial cells are still present surrounding the ducts. The amount of sclerosis is variable and it can go from focal to diffuse. It is more frequent to find microcalcifications associated with sclerosing papillomas than with nonsclerosing papillomas [27].

Sonographically, these lesions present with a round or an oval shape and circumscribed margins. They tend to have coarse calcifications whereas papillary carcinomas have larger solid components [28]. Dilated ducts are common ultrasonographic features in these lesions and this helps to differentiate papillomas from other benign breast lesions such as fibroadenomas [14] (Figure 6).

It has been reported that there is a higher risk of malignancy when peripheral ductal ectasia, ductal ectasia extending to an elongated area, ill-defined ductal thickening with mammary ductal ectasia or hypoechoic fibroglandular tissue are found [13]. 
Clinically significant papillomas are visible in MRI, yet no pathognomonic features have been described. These lesions can be suspected when a mass is associated with a dilated duct; however, this does not define a lesion as benign or malignant. Other characteristics that have been described are round, oval or lobulated masses with smooth margins and type 2 or 3 time intensity curves [29]. Kurz et al. concluded that including a systematic breast MRI to diagnostic protocols of papillomas correctly characterized them as benign [29]. A combined protocol of dynamic contrast enhanced MRI and Diffusion-weighted imaging (DWI) sequences has provided $100 \%$ sensitivity and $65.2 \%$ specificity for the diagnosis of papillary breast lesions. Yildiz et al. reported that DWI should not be used by itself but as a complement when a diagnosis of PBL is confirmed by core biopsy to help decide whether to excise the lesion. They reported that malignant lesions had a statistically significant association with lower mean Apparent Diffusion Coefficient values than benign lesions. So lesions with greater Apparent Diffusion Coefficient values may be followed up in order to avoid an unnecessary surgical procedure [15].

Recent studies have shown that these lesions have the potential of gradual transformation to carcinomas or papillary DCIS with an incidence of upgrade ranging from $0-16 \%$ [30].

Management for these lesions is quite controversial. Traditionally, they have been managed surgically; however, some authors have proposed benign papillary lesions should not be excised if there is no atypia or discordance between imaging and histologic findings [14,30,31]. Some of the features that have supported close observation are women less than 55 years of age and mass size less than $1 \mathrm{~cm}[6,32]$. When an excisional biopsy is not performed, a follow-up with mammography and ultrasound every 6 months for 2 years and annually after that has been recommended [33].

The incidence of invasive carcinoma following excision is $2 \%$ or less in the ipsilateral breast, $2 \%$ or less in the contralateral breast and $0.3 \%$ for bilateral neoplasms. These data support the decision of not performing extensive surgery after benign papillomas have been diagnosed by excisional biopsy [33].

The event-free survival of papillomas without atypia has been reported at $96 \%$, compared with $77 \%$ for papillomas with atypia. This confirms that findings of atypia are associated with a higher risk of recurrence or developing upgraded lesions in a long-term follow-up [18].

\section{Atypical papillary lesions}

Pathologically these lesions are defined as papillomas with few or no myoepithelial cells and foci of monotonous cells with features of low grade ductal neoplasia [34]. Atypia in papillomas is usually low nuclear grade [8]. These lesions can be divided into intraductal papilloma with atypical hyperplasia or intraductal papilloma with DCIS [7]. If the area of atypia is less than $3 \mathrm{~mm}$, papilloma with $\mathrm{ADH}$ is diagnosed. On the contrary, when atypia is large $(>3 \mathrm{~mm})$, the term intraductal papilloma with DCIS is warranted $[8,19]$. Recent literature suggests that giving the term papilloma with DCIS to abnormal epithelial proliferation with intermediate or high nuclear grade regardless the extent of atypia [35]. Immunohistochemistry is useful to make distinctions regarding the extent of atypia [8].

Histological distinction between benign and atypical lesions is still difficult because of sampling errors, limited amount of material and heterogeneity of the tissue [11].

It has been described that central papillomas have a lower chance of association with atypia (0-15\%). Conversely, multiple papillomas which are more commonly peripherally located, have a higher risk of atypia and malignancy $(32-72 \%)[25,27]$.

Imaging characteristics are similar to those described for benign lesions. When imaging findings are present, they can be seen as circumscribed benign appearing masses or clusters of calcifications, which is less common. On ultrasound these findings may be seen as hypoechoic, well-defined, circumscribed masses [25].

Underestimation in image-guided core needle biopsy has been reported in 13-92\% of cases which supports surgical management of these lesions due to high risk of carcinoma [26,31,36].

\section{Papillary carcinoma}

Papillary carcinoma accounts for $0.5-1 \%$ of all breast cancers [37]. Clinically these lesions present in postmenopausal women as a nipple discharge and/or a painless subareolar mass [37]. A total of $89.6 \%$ of papillary carcinomas are localized, whereas $7.8 \%$ have regional disease with local spread and $0.4 \%$ have distant metastatic disease [37].

Pathologically papillary carcinomas can be divided in invasive and noninvasive types. Noninvasive papillary carcinomas are subdivided into EPC, SPC and papillary ductal carcinoma in situ. The invasive types of carcinomas are divided into papillary and micropapillary carcinomas [7]. It is important to differentiate between invasive and noninvasive types of papillary carcinomas because of the prognostic significance [38]. 

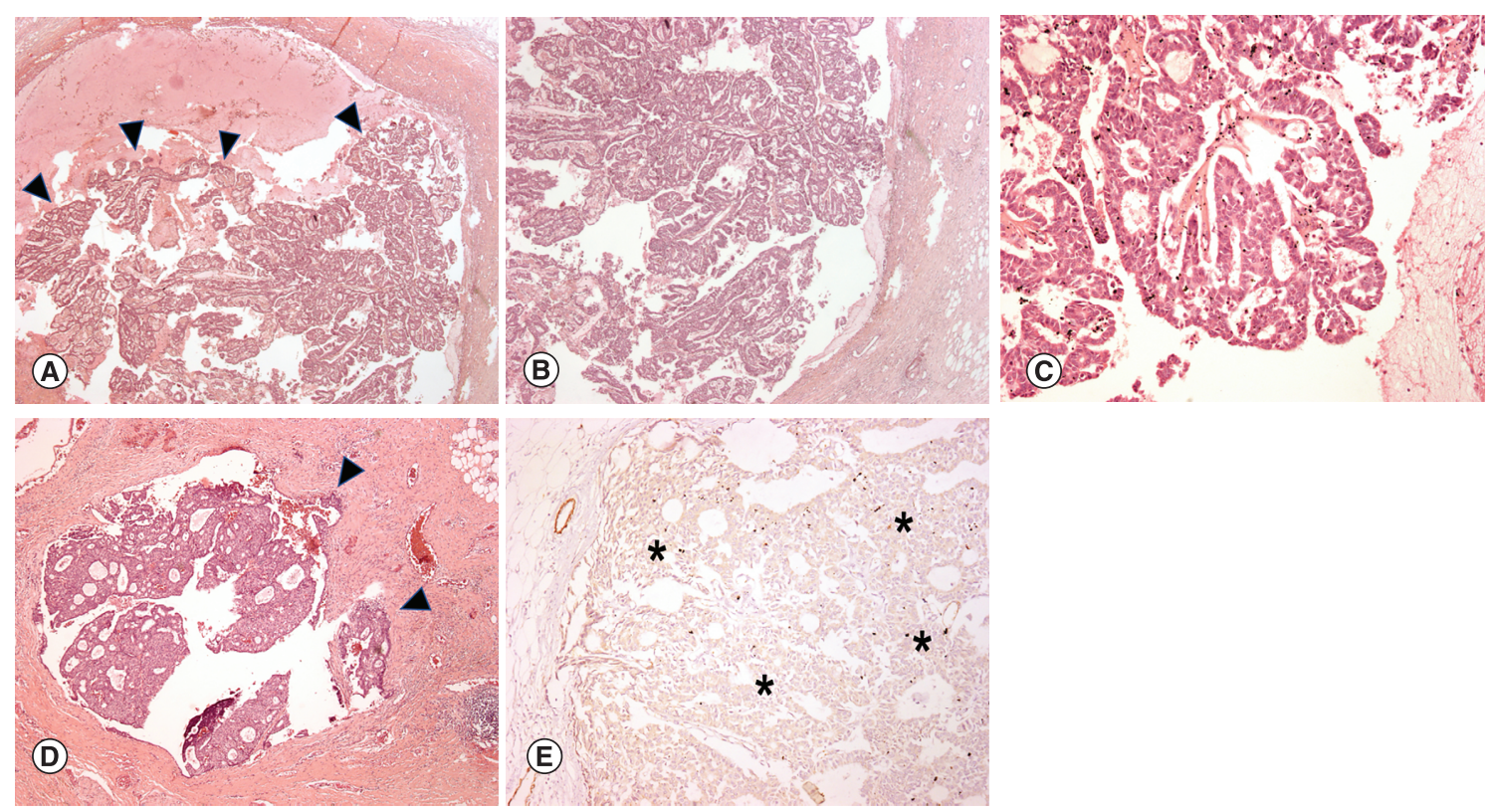

Figure 7. Intraductal papillary carcinoma. (A) Hematoxylin-eosin, original magnification $\times 100$. Well defined lesion composed by complex papillary proliferations (arrowheads). (B) Hematoxylin-eosin, original magnification $\times 100$ shows epithelial cells lined in papillary lesion with homogeneous size, hyperchromatic and stratified nuclei. (C) Hematoxylin-eosin, original magnification $\times 400$. Atypia is demonstrated. (D) Hematoxylin-eosin, original magnification $\times 100$ shows stromal invasion by epithelial cells (arrowheads). (E) Immunohistochemistry, original magnification $\times 100$ demonstrates the absence of myoepithelilal cells in the papillary proliferations with myoepithelial cells in the duct (asterisk).

Papillary carcinomas are defined by the complete or almost complete absence of myoepithelial cells in the papillary fronds of the intraductal proliferations [5]. Myoepithelial cells are frequently absent in EPC and SPC (80\% of the cases) and always absent in invasive carcinoma [8] (Figure 7).

In these cases the papillae are more delicate and less fibrotic than in benign papillomas. Epithelium is composed by a single cell population with an homogeneous appearance as opposed to benign lesions were heterogeneous presentation of the cell components is expected. The architecture is predominantly flat, solid or cribriform with polarization of proliferating neoplastic cells. Increased mitotic figures are found [8].

On imaging, there are some characteristics that are more common in papillary carcinoma. On ultrasound we can classify as three main appearances including an intraductal mass with or without ductal dilatation, an intracystic mass or a solid lesion with an intraductal component. These lesions tend to have a larger solid component and a higher frequency of spontaneous bleeding compared with benign papillomas. Masses usually have a nonparallel orientation, an echogenic halo or posterior acoustic enhancement that can be associated with microcalcifications. These ultrasound features have a sensitivity of $85.7 \%$ and a specificity $64.9 \%$ for a malignant papillary lesion [28]. Other features associated with specific subtypes of papillary carcinoma are masses with intraductal extension obstructing peripheral ducts and radial projections from the mass to the nipple.

Published data on MRI findings is still scarce; however, some authors have reported nonmass enhancement as a finding related to malignancy [13].

There are other imaging features that can orientate to a specific subtype of papillary carcinoma which are going to be discussed below.

\section{Papillary ductal carcinoma in situ}

Papillary DCIS also called intraductal carcinoma, is a variant of DCIS and is a term given by the WHO [9]. It is defined as an in situ malignant papillary lesion without recognizable papilloma morphological characteristics. On the contrary, papilloma with DCIS (discussed previously in the atypia section) shows a benign papilloma upon which abnormal epithelial proliferation can be seen [35]. 


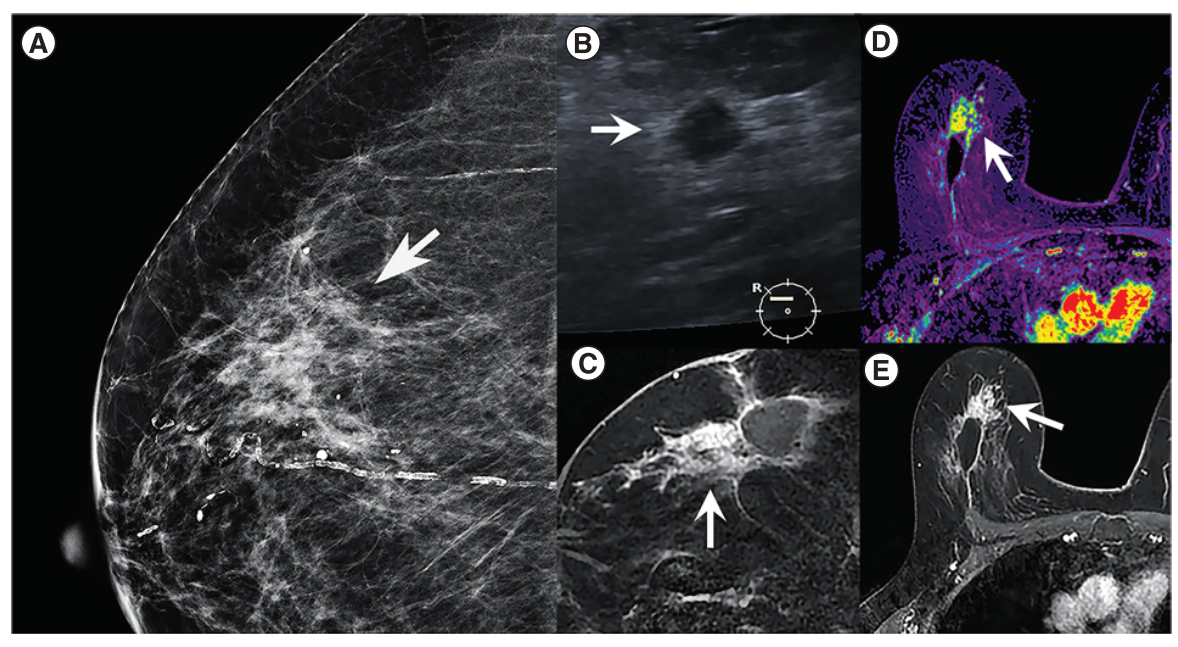

Figure 8. Papillary ductal carcinoma in situ. (A) Craniocaudal view shows an isodense, oval, circumscribed mass in the upper outer quadrant of the right breast (arrow). (B) Axial grayscale ultrasound demonstrates a solid, oval, nonparallel, hypoechoic mass (arrow). A biopsy was performed and papillary DCIS was reported. (C-E) Contrast enhanced sagittal and axial substraction of the right breast of the same patient 4 months later showed surgical changes and segmental nonmass enhancement in the right breast (arrows). Biopsy was repeated and residual papillary ductal carcinoma in situ was reported.

Papillary DCIS usually has a peripheral location, can be multifocal and can be associated with other variants of DCIS [8]. Compared with other DCIS subtypes, papillary DCIS has a higher recurrence rate, which is why some authors recommend mastectomy rather than breast conserving therapy [39].

Clinically papillary DCIS usually presents as palpable masses or nipple discharge [5].

Pathologically papillary DCIS has a complete or near-complete absence of myoepithelial cells in papillary fronds [5]. Usually the neoplastic cells are of intermediate or high nuclear grade and apocrine differentiation may be present [8]. Under low magnification these lesions have a disorganized architecture with a high amount of fronds that present with variable sizes and shapes. Neoplastic cells always have atypia. Cytologic characteristics in most of these papillary neoplasms are similar to the ones seen in low grade ductal carcinoma in situ. Cells are usually big, have a polygonal shape and round hyperchromatic nuclei with broad cytoplasm. In these case mitotic figures are found easily. These lesions are composed by multiple layers forming cribriform spaces and trabeculae. Neoplastic cells in these cases can proliferate and blur papillary architecture, thus making a papilloma seem like a solid lesion. High magnification is used to identify fibrovascular structures that support these lesions. In these cases apocrine metaplasia is absent $[40,41]$. The WHO recommends the use of two to three antibody panels on immunohistochemistry to demonstrate myoepithelial cells. P63, CK14 and CK5 are useful myoepithelial markers [35].

Imaging findings in papillary DCIS are nonspecific but can show pleomorphic or amorphous calcifications in a regional or a segmental distribution on mammography. Ultrasound has a limited value and can show no abnormalities even if the tumor is extensive. If a mass is found, it usually presents as hypoechoic, parallel, with irregular margins and it can have an echogenic halo or posterior acoustic enhancement [39] (Figure 8). It can also be associated with microcalcifications [5,19].

Magnetic resonance has not been well studied in these lesions but it has been reported that findings can be segmental or regional non-mass enhancement. It is important to recognize that mammography and ultrasound both underestimate tumor size, while MRI is the most accurate imaging study for size estimation [39].

\section{Encapsulated papillary carcinoma}

Encapsulated papillary carcinoma is the preferred terminology for the previously known intracystic or encysted papillary carcinoma and accounts for $0.5-1 \%$ of breast carcinomas [42].

These lesions are similar to intraductal papillomas and traditionally they have been classified as noninvasive tumors although recent literature has proposed an invasive nature due to the fact that there is an absence of myoepithelial cells in the tumor-stromal interface [43]. Originally these lesions were classified as a variant of ductal carcinoma; however, it is now known that they can be associated with invasive components, thus being classified as 


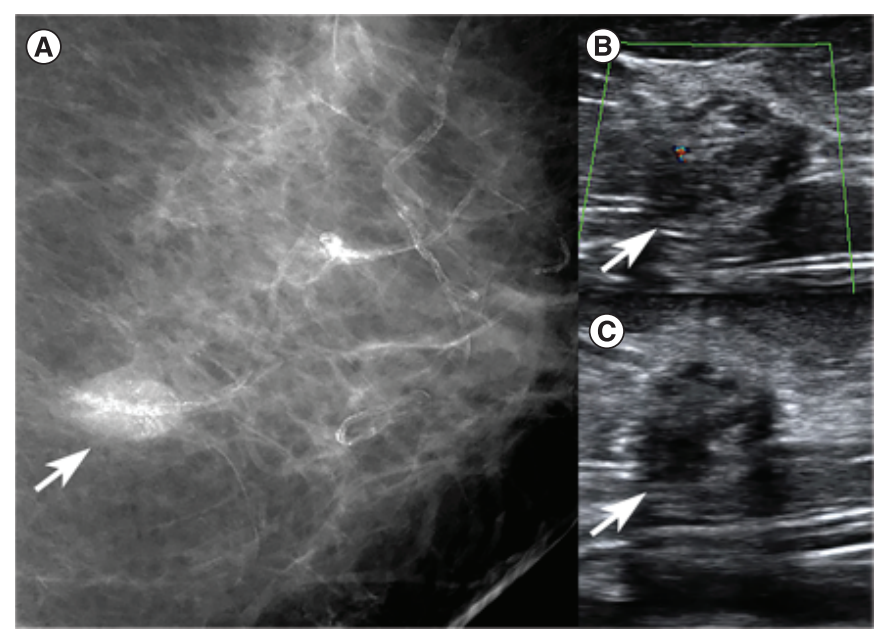

Figure 9. Encapsulated carcinoma. (A) Craniocaudal view of the left breast shows an oval isodense mass with pleomorphic calcifications (arrow) (B \& C) Axial grayscale and Doppler ultrasound demonstrate an irregular, nonparallel, complex lesion with shadowing and absent vascularity (arrows). Pathology reported encapsulated papillary carcinoma.

a separate entity. In 2012 the WHO classified encapsulated papillary carcinoma as a subgroup of papillary breast lesions and a type of breast papillary carcinoma [44,45]. They are usually reported in elderly patients with a mean age of 65 years. The size of the tumor ranges from 1-10 cm [46]. Clinically, EPC can present as a palpable mass, nipple discharge or an asymmetry [47]. Pathologically, EPC is defined by a tumor with no myoepithelial cells in the periphery of the lesion and a fibrous capsule that separates it from the rest of the mammary stroma [43]. Neoplastic cells can be low or intermediate grade [8]. EPC can be associated with DCIS or invasive ductal carcinoma [44]. In the absence of invasive elements these lesions have an excellent prognosis with a mean survival rate of 60-95\% for in situ EPC [47]. The frequency of lymph node involvement is up to $11 \%$ and distant recurrence has a frequency of up to $4 \%$, whereas local recurrence frequency goes up to $70 \%$ [46].

For pure EPC, it has been documented that local surgical excision (lumpectomy) may be enough when surgical margins are negative. When EPC is associated with DCIS or an invasive component, axillary lymph node dissection and adjuvant treatment are considered [47]. Hormonal therapy is thought to be useful as EPC has a high frequency of positive estrogen and progesterone receptors. The role of radiotherapy still remains unclear [47].

EPC usually presents on mammogram as a solitary round, oval or lobulated well- defined retroareolar or central mass ( $50 \%$ of the cases) that can have microcalcifications or satellite lesions [47]. Ultrasound is the imaging modality of choice and it can present as a mixed type of lesion with cystic and solid components that can have internal vascularity, posterior acoustic shadowing or posterior acoustic enhancement [46,48] (Figure 9). Irregular margins suggest an invasive component [5,47].

MRI findings have not been well documented for EPC but it has proven helpful for detection of DCIS around the lesion [46]. As mentioned previously, a pure EPC can be treated with lumpectomy, thus to avoid unnecessary mastectomies MRI plays a key role in surgical planning [44]. Most of these lesions appear as a round or oval mass with circumscribed margins that correspond to the thick fibrous capsule. On T1 weighted images they appear isointense and they are hyperintense on T2 weighted images. Mural masses and hemorrhage within the lesion can help make a diagnosis of EPC [44].

\section{Solid papillary carcinoma}

Solid papillary carcinoma accounts for less than $1 \%$ of breast neoplastic lesions [49]. This is a rare entity that is composed by low grade tumors that originate in large dilated ducts. They are considered in situ carcinomas by the WHO classification although some authors classify them as invasive because of their lack of myoepithelial cells [9,50]. At the time of diagnosis, 90\% have localized involvement, $8 \%$ regional disease and $0.4 \%$ distant metastases [51].

Neuroendocrine DCIS is a synonym for solid papillary breast carcinoma but it is important to recognize that $\mathrm{SPC}$ is not equal to a neuroendocrine carcinoma [49].

Although there are no specific clinical features, these lesions can present as palpable masses or nipple discharge with an indolent course [50]. They usually present in elderly women with a mean age of 62 years. The outcome of this type of papillary lesion is excellent with a low rate of mortality [49]. Risk of local recurrence is very low and lymph node metastases has not been reported [52]. These tumors usually arise from the central area of the breast, $95 \%$ are unilateral and size varies from $1-15 \mathrm{~cm} \mathrm{[50].}$ 
Figure 10. Solid papillary carcinoma. (A) Craniocaudal view of the right breast shows an oval, circumscribed, hyperdense mass in the central breast. (B \& C) Transverse and sagittal grayscale ultrasound demonstrates an irregular, nonparallel, heterogeneous mass. Biopsy was performed and solid papillary carcinoma was reported.

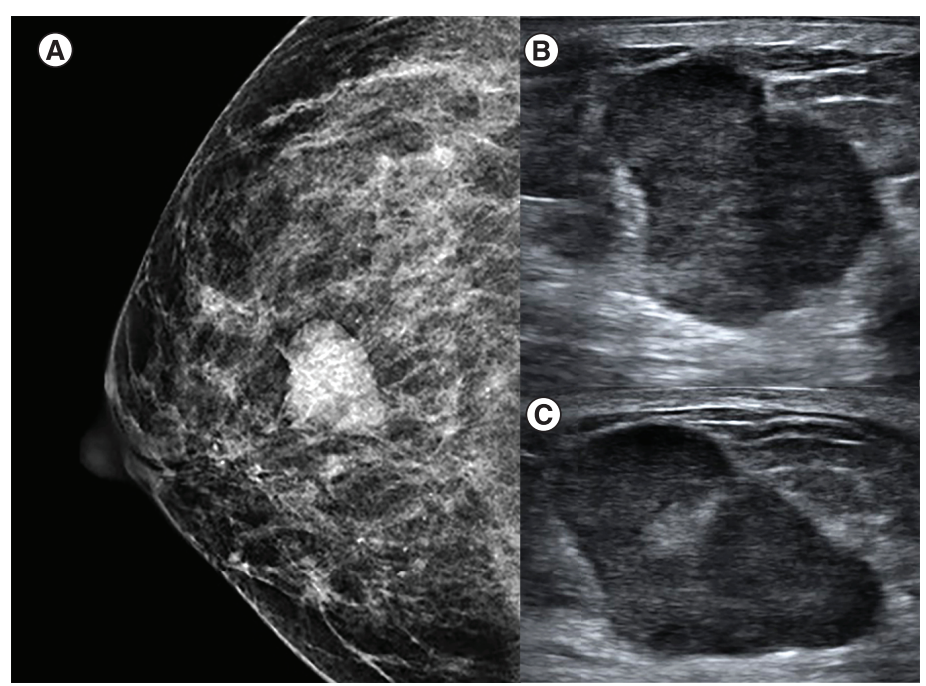

Pathologically SPC is defined as a round mass with low grade ductal cells which are separated by fibrovascular cores. Most of these tumors have no peripheral myoepithelial cells. Tan et al. reported that when myoepithelial cells are demonstrated around the epithelial masses they are considered variants of DCIS [35]. Neoplastic cell differentiation in these cases is of intermediate grade, which at low magnification simulates ductal hyperplasia. Under high magnification, monotonous proliferation of neoplastic cells can be seen, as well as a high number of mitotic figures. SPC is usually solid with mucin production, multinodular architecture and neuroendocrine features. Proliferation index is usually low. It is more frequent to find a co-existing invasive carcinoma associated with SPC than to EPC [8,50]. It is recommended to report whether SPC is associated with in situ or invasive components and not give a diagnosis of SPC by itself in order to avoid ambiguity [35].

There are no specific imaging characteristics but there are some features that may suggest this lesion. Mammography usually shows a high density, rounded or oval, well circumscribed mass. When associated with invasive components, SPC can also present as an ill defined mass [52]. Ultrasound is the most sensitive method for papillary lesions and may suggest and homogeneous hypoechoic solid lesion, a complex intracystic lesion or frond-like masses within dilated ducts [50] (Figure 10). SPC can be associated with posterior acoustic enhancement or microcalcifications [51].

MRI is not specific but is sensitive for detecting round or oval masses with well defined margins [51]. The majority of the tumors show hyperintensity on T2-weighted images [53]. There are other features like septations, enhancement of the wall or mural masses that can also be seen [51].

There are no guidelines for the treatment of SPC but surgical excision is recommended specially if atypia or invasive components have been demonstrated. Although the role of sentinel lymph node biopsy is still not clear, some authors suggest sentinel lymph node biopsy because of SPC's association with axillary lymph node metastases. If imaging studies demonstrate a well circumscribed localized tumor with no evidence of invasion and a negative axillary ultrasound, performing a mastectomy with axillary dissection is considered overtreatment, with breast conservation surgery thought to be the optimal management. Hormonal therapy and radiotherapy are still controversial [51].

\section{Invasive papillary carcinoma}

This term is given to infiltrating carcinomas that should not be confused with micropapillary carcinoma which is a separate entity that will be discussed below [28]. These tumors account for less than $2 \%$ of all breast cancers and are defined by having a papillary architecture in more than $90 \%$ of an invasive tumor $[7,54]$.

They present in postmenopausal women between the sixth and eighth decade as bloody nipple discharge or a palpable mass [55,56].

The mammography can show a round, oval or lobulated high density mass with circumscribed margins. Usually the invasive component cannot be detected by this method. Ultrasound can show a complex cystic and solid mass that can have increased vascularity in solid areas [56,57] (Figure 11). 


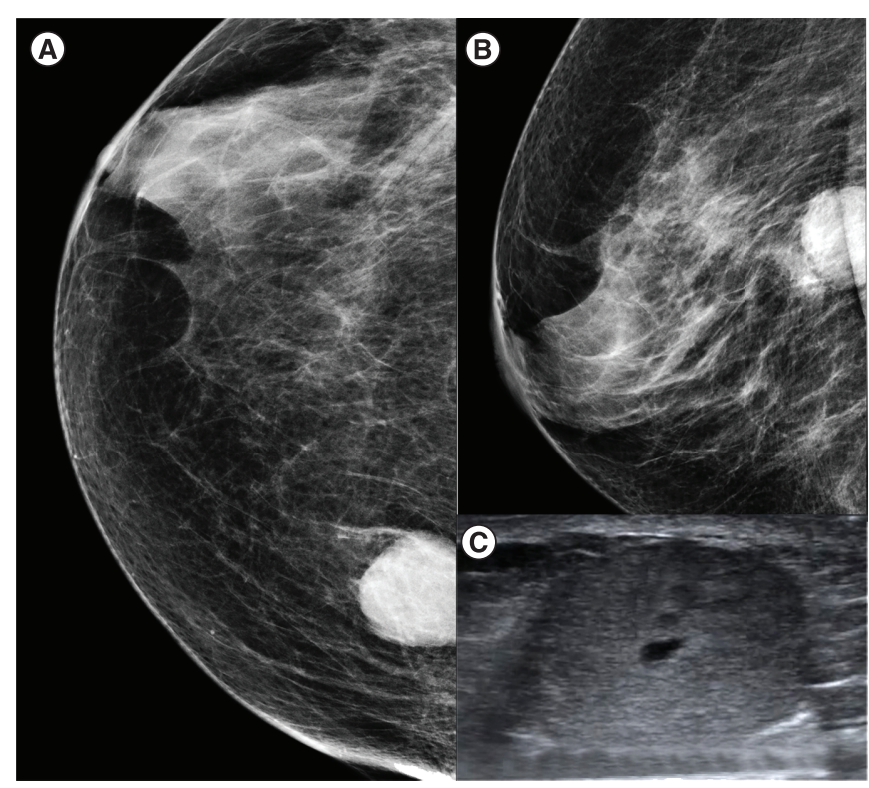

Figure 11. Invasive papillary carcinoma. (A \& B) Craniocaudal and mediolateral oblique views of the right breast show a round, hyperdense circumscribed mass. (C) Transverse grayscale ultrasound demonstrates an oval, heterogeneous, parallel mass. Pathology reported invasive papillary carcinoma.

Pathologically invasion is described as neoplastic cells with infiltrative appearance that extends beyond reactive stroma and into mammary fat and parenchyma [8]. These tumors have no myoepithelial cells which can be identified by immunohistochemical markers. P63 and smooth muscle myosin heavy chain are specific markers, but there are other nonspecific ones like calponin, alfa smooth muscle actin, S-100, maspin, CD10 and high molecular weight cytokeratin [55].

It is important to note that neither EPC nor SPC associated with invasive components should be classified as invasive papillary carcinoma but instead categorized according to the individual invasive component [58]. Almost all of these tumors express estrogen and progesterone receptors, while being C-erbB2-negative, corresponding to a luminal A- like subtype [58,59]. This type of carcinoma has a low recurrence rate and longer disease-free interval [58]. Treatment for invasive carcinomas can be divided in local or systemic [55]. Even if IPC has a slow disease progression, lumpectomy remains standard treatment [58].

\section{Invasive micropapillary carcinoma}

This carcinoma usually presents in the sixth decade and it is an aggressive variant of invasive carcinoma. The incidence of these tumors is low, accounting for only $2.7 \%$ of all papillary carcinomas [60]. The important feature of this type of carcinoma is that this one usually has axillary lymph node metastases and angiolymphatic invasion [55,61]. These tumors can measure from 1.5 to $3.9 \mathrm{~cm}$ which is an average size compared with other papillary lesions [62]. Pathologically this carcinoma is characterized by micropapilae composed by neoplastic cells that lack a central vascular stalk. These cases are usually low or intermediate grade tumors (Figure 12). Imaging features are highly suggestive of malignancy and include irregular high density masses with spiculated margins in mammograms, with or without microcalcifications. Ultrasound findings can show an irregular hypoechoic spiculated mass. It is important to do an ultrasound of the axilla because of the association with lymph node metastases, which is up to 59\% [61] (Figure 13). MRI can also show irregular masses with rapid initial washout kinetic curves. Some authors have described nonmass enhancement in the breast [61 ]. These tumors have $93 \%$ of positivity for estrogen receptors and $73 \%$ progesterone receptor positivity, corresponding to a higher incidence than other invasive ductal carcinomas [61].

Because clinical presentation and imaging features have no significant difference from invasive ductal carcinoma, the final diagnosis depends on pathology evaluation. More than $50 \%$ of the tumor components should be constituted by micropapillary architecture for the diagnosis to be established [62]. Although lymph node invasion is the most important prognostic predictor, the 5 year overall survival of these patients has increased to $89 \%$ [62]. Mortality rate in these variant goes from 8 to $37 \%$ with a relapse rate up to $71 \%$ [61].

Currently, breast conservation with sentinel node biopsies has been gaining popularity for stage I and II tumors. Pathology results from the sentinel lymph node biopsy guide further management [62]. Recently, subtypes of IMPC 
Figure 12. Invasive micropapillary carcinoma. (A) Hematoxylin-eosin, original magnification $\times 100$.

Distortion of architecture associated with micropapillary proliferation is demonstrated as well as neoplastic cells that infiltrate diffusely. (B) Hematoxylin-eosin, original magnification $\times 400$. Neoplastic cells (asterisk) with high grade nuclei of variable sizes, hyperchromasia and eosinophilic cytoplasm. (C) Immunohistochemistry original magnification $\times 1000$ demonstrates the groups of neoplastic cells expressing MUC-1 which highlights the micropapillary contours (arrowheads). (D) Immunohistochemistry original magnification $\times 400$. Expression of epithelial membrane antigen is shown (arrowheads).
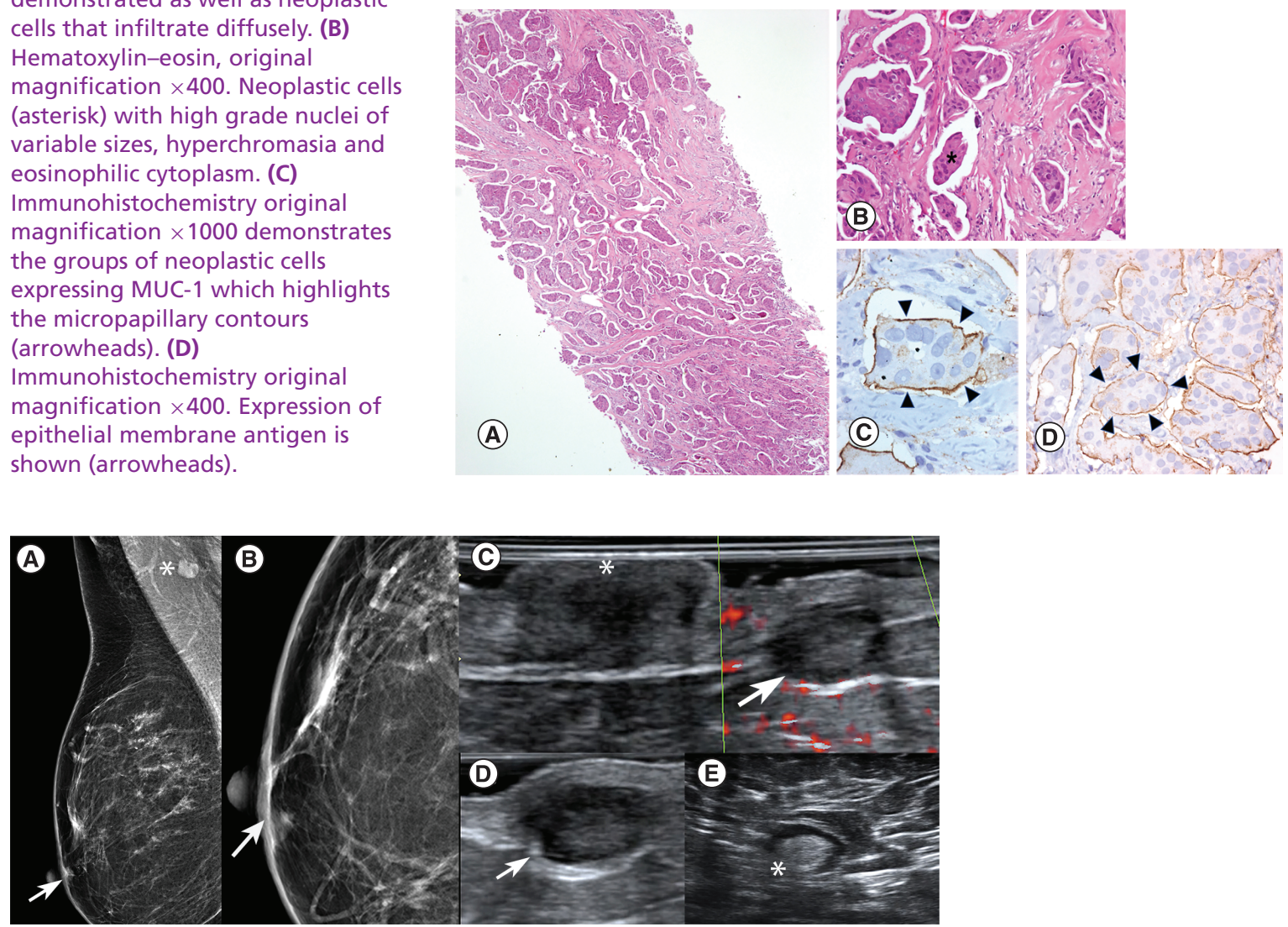

Figure 13. Invasive micropapillary carcinoma. (A \& B) Mediolateral oblique and magnified craniocaudal views of right breast show segmental fine pleomorphic calcifications in the upper outer quadrant and a periareolar oval, hyperdense circumscribed mass (arrow). Adenopathy in the right axilla can also be seen (asterisk). (C \& D) Transverse and sagittal grayscale and color Doppler ultrasound demonstrate a retroareolar, oval, parallel, hypoechoic, mass with indistinct margins (arrows). Note the proximity to the nipple $\left(^{*}\right)(E)$ Transverse grayscale ultrasound demonstrates the right axillary adenopathy. Biopsy was performed in the breast nodule and the axillary lymph node shown in Figure (E) and invasive micropapillary carcinoma was diagnosed.

have been described including IMPC with mucinous differentiation and invasive mucinous carcinoma with a micropapillary carcinoma growth pattern but prognostic significance of these variants is still not clear [62].

\section{Future perspective}

Recently, many authors have discussed the need for standardized management in regards to intraductal papillomas. Upstaging rates to malignancy are variable and the necessity of routine excision has been questioned [63]. No standard management has been established and recommendations are not uniform for benign lesions [33]. It is important to mention that different biopsy methods affect upgrade rates [64]. Even though core needle biopsy is usually the procedure of choice, underestimation and false negatives is a disadvantage of this technique [65]. Some authors have suggested that a diagnosis of papillary lesion given by a CNB should be followed by a VAB. This could be an alternative to surgery; however, for a routine management, it is expensive [65-67]. When a VAB is initially performed, underestimation rates are reduced, as opposed to using other biopsy methods. Upgrade rates are higher when a CNB is performed than using VAB [64]. VAB is considered an acceptable method for excision in benign lesions [68]. In the Second International Consensus Conference on lesions of uncertain malignant potential in the breast (B3 lesions) it was recommended that papillomas should undergo excision with VAB. In case these lesions 
are large and cannot be completely excised with VAB, open excision is needed [69]. This supports the trend toward less open surgery in benign papillary lesions for future management $[69,70]$.

When speaking of lesions showing atypia or neoplastic cells, surgical excision is clearly justified after a CNB and no changes in this management are expected soon [71]. Some authors have reported that papillomas with mammographic abnormalities were related to higher upgrade rates, specially when a mass was found and an ultrasonographic correlation was demonstrated [72-74]. Further research in this area should be encouraged.

Currently, there are no reliable features to differentiate benign from malignant lesions in high-risk lesions detected by MRI. Nevertheless, Ring et al. suggests that in a specific subset of benign breast lesions, apocrine metaplasia was commonly seen in papillary and sclerosing lesions of the breast and may contribute to enhancement and adjacent T2 hyperintensity. There are several studies that have examined the upgrade rate of papillary and sclerosing lesions. Ring et al. determined an upgrade rate of MRI-detected papillary lesions of 6\%, similar to other studies. Heller et al. documented an upgrade rate of $8 \%$ for papillary lesions. These results may suggest that recent guideline recommendations might also apply on high-risk patients with papillary and sclerosing lesions detected and biopsied by MRI-VAB [75,76]. Histologic diagnosis of papillary lesions is still challenging. Immunohistochemistry has been used to improve diagnostic accuracy; however, the efficacy of this method is still being investigated [21].

It is well known that having IDP confers risk of developing breast cancer; however, studies suggest these lesions could only progress into papillary carcinoma. Nevertheless, there is no evidence of why IDP has been found coexisting with nonpapillary forms of ductal carcinoma in situ and invasive ductal carcinoma. It has been demonstrated that up to $37 \%$ of core biopsy-diagnosed atypical IDP include DCIS or IDC upon surgical excision [77]. Kader et al. recently published data suggesting that IDP with no copies number alterations (CNA), independently of the histological subtype, clinical data or age of the patient, lack malignant progression potential. This evidence arises the possibility to avoid surgical excision in these patients [78]. It has also been demonstrated IDP may progress directly into DCIS and IDC of any grade, showing that these different entities can share molecular genetic features and have a common etiology [79]. Atypical IDPs carry a higher risk of being clonal with synchronous cancer compared with benign IDP. The presence of particular CN events, specifically $16 \mathrm{q}$ loss, 1q gain and $11 \mathrm{q}$ loss can help differentiate clonal IDP from nonclonal and pure IDP [80]. These CN alterations have been commonly found also in papillary and ductal carcinoma. The PIK3CA mutation has been found in benign and atypical IDPs as well as in ductal carcinomas, but it is uncommon in PC and IDC that arise in the background of IDP [81,82]. It has also been reported that this mutation is present in several early breast lesions generating cellular proliferation rather than conferring malignant potential [83]. This evidence is supported by the fact that different overgrowth syndromes that have no malignant transformation potential also present this mutation [84].

This information suggests that the absence of CNA (16q loss, 1q gain, 11q loss) and the presence of PIK3CA mutation in IDPs may be a biomarker of low risk for malignant transformation, regardless of pathologic features (benign or atypical IDP) and clinical findings. Further studies are needed to confirm these data [78]. With molecular biomarkers advances, a genome-wide CNA and/or targeted mutation analysis should be considered as the presence/absence of CNA (16q loss, 1q gain, 11q loss) and PIK3CA mutation may serve as potential biomarkers for predicting malignant progression/transformation. Nevertheless, more evidence is needed in order to consider this the appropriate next step. Up until now, in the absence of a consensus and in the setting of atypical papillomas, surgical excision is still warranted.

\footnotetext{
Financial \& competing interests disclosure

The authors have no relevant affiliations or financial involvement with any organization or entity with a financial interest in or financial conflict with the subject matter or materials discussed in the manuscript. This includes employment, consultancies, honoraria, stock ownership or options, expert testimony, grants or patents received or pending, or royalties.

No writing assistance was utilized in the production of this manuscript.
}

Open access

This work is licensed under the Attribution-NonCommercial-NoDerivatives 4.0 Unported License. To view a copy of this license, visit http://creativecommons.org/licenses/by-nc-nd/4.0/ 
Benign papillary lesions

- A total of $70-85 \%$ of all papillary breast lesions.

- They can be central (most common) or peripheral.

- Usually in woman between 35-55 years.

- Most common cause of nipple discharge.

- Ultrasound characteristics: round or oval shape with circumscribed margins that can be associated with dilated ducts.

- MRI characteristics: round, oval or lobulates masses with type 2 or 3 time intensity curves.

- These lesions have potential for malignant transformation ranging from $0-16 \%$.

- Management is controversial and some authors have proposed follow-up when the patient is less than 55 years and the lesion is less than $1 \mathrm{~cm}$.

Atypical papillary lesions

- Papillomas with few or no myoepithelial cells.

- Imaging characteristics are similar to benign papillomas.

- Management is always excision due to high risk of carcinoma.

Papillary carcinoma

- Can be invasive or noninvasive.

- Defined by the absence of myoepithelial cells.

- Papillary ductal carcinoma in situ is a noninvasive type of cancer and should not be confused with papilloma with ductal carcinoma in situ. It can show pleomorphic or amorphous calcifications. They have peripheral location and are usually multifocal.

- Encapsulated papillary carcinoma is noninvasive papillary carcinoma and it is frequently solitary and centrally located. Ultrasound is the modality of choice and may appear as a mixed type of lesion with cystic and solid components.

- Solid papillary carcinoma is noninvasive and these are usually unilateral and centrally located. Can show as a high density, rounded or oval well circumscribed mass.

- Invasive carcinomas include invasive papillary carcinoma and invasive micropapillary carcinoma (IMPC). Invasive papillary carcinoma usually presents as a round, oval or lobulated mass whereas IMPC has spiculated margins and can be associated with microcalcifications. IMPC usually has axillary lymph node metastases which confers a worse prognosis.

\section{References}

Papers of special note have been highlighted as: • of interest; $\bullet \bullet$ of considerable interest

1. Kuehner G, Darbinian J, Habel L et al. Benign papillary breast mass lesions: favorable outcomes with surgical excision or imaging surveillance. Ann. Surg. Oncol. 26(6), 1695-1703 (2019).

2. Brookes MJ, Bourke AG. Radiological appearances of papillary breast lesions. Clin. Radiol. 63(11), 1265-1273 (2008).

3. Chen P, Zhou D, Wang C, Ye G, Pan R, Zhu L. Treatment and outcome of 341 papillary breast lesions. World J. Surg. 43(10), 2477-2482 (2019).

4. Bloom C. Breast papillomas: a comprehensive review. J. Diagn. Med. Sonogr. 31, 282-289 (2015).

- Complete imaging review of papillary lesions.

5. Wei S. Papillary lesions of the breast: an update. Arch. Pathol. Lab. Med. 140(7), 628-643 (2016).

6. Hong YR, Song BJ, Jung SS, Kang BJ, Kim SH, Chae BJ. Predictive factors for upgrading patients with benign breast papillary lesions using a core needle biopsy. J. Breast Cancer 19(4), 410-416 (2016).

7. Basavaiah SH, Minal J, Sreeram S et al. Diagnostic pitfalls in papillary lesions of the breast: experience from a single tertiary care center. $J$ Clin. Diagn. Res. 10(8), EC18-EC21 (2016).

- Pathologic classification in which this article is based.

8. Rakha EA, Ellis IO. Diagnostic challenges in papillary lesions of the breast. Pathology 50(1), 100-110 (2018).

-. Updated 2017 pathologic review.

9. Jorns JM. Papillary lesions of the breast: a practical approach to diagnosis. Arch. Pathol. Lab. Med. 140(10), 1052-1052 (2016).

10. Ni YB, Tse GM. Pathological criteria and practical issues in papillary lesions of the breast - a review. Histopathology 68(1), 22-32 (2016).

11. Xia HS, Wang X, Ding H, Wen JX, Fan PL, Wang WP. Papillary breast lesions on contrast-enhanced ultrasound: morphological enhancement patterns and diagnostic strategy. Eur. Radiol. 24(12), 3178-3190 (2014).

12. Tse GM. Papillary lesions of the breast. Diagn. Histopathol. 24(2), 64-70 (2018). 
13. Sarica O, Dokdok M. Imaging findings in papillary breast lesions: an analysis of ductal findings on magnetic resonance imaging and ultrasound. J. Comput. Assist. Tomogr. 42(4), 542-551 (2018).

14. Lam WW, Chu WC, Tang AP, Tse G, Ma TK. Role of radiologic features in the management of papillary lesions of the breast. AJR Am. J. Roentgenol. 186(5), 1322-1327 (2006).

15. Yildiz S, Toprak H, Ersoy YE et al. Contribution of diffusion-weighted imaging to dynamic contrast-enhanced MRI in the characterization of papillary breast lesions. Breast J. 24(2), 176-179 (2018).

-. Importance of DWI in papillary lesions and the use of MRI to prevent unnecessary excisional biopsies.

16. Koerner F. Papilloma and papillary carcinoma. Semin. Diagn. Pathol. 27(1), 13-30 (2010).

17. Boin DP, Baez JJ, Guajardo MP et al. Breast papillary lesions: an analysis of 70 cases. Ecancermedicalscience 8, 461 (2014).

18. Chen P, Zhou D, Wang C, Ye G, Pan R, Zhu L. Treatment and outcome of 341 papillary breast lesions. World J. Surg. 43(10), 2477-2482 (2019).

19. Eiada R, Chong J, Kulkarni S, Goldberg F, Muradali D. Papillary lesions of the breast: MRI, ultrasound and mammographic appearances. AJR Am. J. Roentgenol. 198(2), 264-271 (2012).

-• Important imaging review of papillary lesions.

20. Lacambra MD, Lam CC, Mendoza P et al. Biopsy sampling of breast lesions: comparison of core needle- and vacuum-assisted breast biopsies. Breast Cancer Res. Treat. 132(3), 917-923 (2012).

21. Qiu L, Mais DD, Nicolas M, Nanyes J, Kist K, Nazarullah A. Diagnosis of papillary breast lesions on core needle biopsy: upgrade rates and interobserver variability. Int. J. Surg. Pathol. 27(7), 736-743 (2019).

22. Chang JM, Han W, Moon WK et al. Papillary lesions initially diagnosed at ultrasound-guided vacuum-assisted breast biopsy: rate of malignancy based on subsequent surgical excision. Ann. Surg. Oncol. 18(9), 2506-2514 (2011).

23. Rovno HD, Siegelman ES, Reynolds C, Orel SG, Schnall MD. Solitary intraductal papilloma: findings at MR imaging and MR galactography. AJR Am. J. Roentgenol. 172(1), 151-155 (1999).

24. Debnath D, Al-Okati D, Ismail W. Multiple papillomatosis of breast and patient's choice of treatment. Patholog. Res. Int. 2010, 540590 (2010).

25. Foley NM, Racz JM, Al-Hilli Z et al. An international multicenter review of the malignancy rate of excised papillomatous breast lesions. Ann. Surg. Oncol. 22(Suppl. 3), S385-S390 (2015).

-• International study that discusses malignancy risk in benign papillary breast lesions to consider in management and avoid surgical treatment when it is not necessary.

26. Boufelli G, Giannotti MA, Ruiz CA et al. Papillomas of the breast: factors associated with underestimation. Eur. J. Cancer Prev. 27(4), 310-314 (2018).

27. Ueng SH, Mezzetti T, Tavassoli FA. Papillary neoplasms of the breast: a review. Arch. Pathol. Lab. Med. 133(6), 893-907 (2009).

28. Pal SK, Lau SK, Kruper L et al. Papillary carcinoma of the breast: an overview. Breast Cancer Res. Treat. 122(3), 637-645 (2010).

29. Kurz KD, Roy S, Saleh A, Diallo-Danebrock R, Skaane P. MRI features of intraductal papilloma of the breast: sheep in wolf's clothing? Acta Radiol. 52(3), 264-272 (2011).

30. Maccoll C, Salehi A, Parpia S, Hodgson N, Ramonas M, Williams P. Benign breast papillary lesions diagnosed on core biopsy: upgrade rate and risk factors associated with malignancy on surgical excision. Virchows Arch. 475(6), 701-707 (2019).

31. Moynihan A, Quinn EM, Smith CS et al. Benign breast papilloma: is surgical excision necessary? Breast J. 26(4), 705-710 (2020).

- Updated literature on management for papillary lesions

32. Ko D, Kang E, Park SY et al. The management strategy of benign solitary intraductal papilloma on breast core biopsy. Clin. Breast Cancer 17(5), 367-372 (2017).

33. Feig SA. Management of papillary lesions of the breast diagnosed by core biopsy: need for an evidence-based standard of care. Breast J. 25(5), 804-806 (2019).

34. Wang H, Tsang P, D'cruz C, Clarke K. Follow-up of breast papillary lesion on core needle biopsy: experience in African-American population. Diagn. Pathol. 9, 86 (2014).

35. Tan PH, Schnitt SJ, Van De Vijver MJ, Ellis IO, Lakhani SR. Papillary and neuroendocrine breast lesions: the WHO stance. Histopathology 66(6), 761-770 (2015).

36. Pareja F, Corben AD, Brennan SB et al. Breast intraductal papillomas without atypia in radiologic-pathologic concordant core-needle biopsies: rate of upgrade to carcinoma at excision. Cancer 122(18), 2819-2827 (2016).

37. Ingle SB, Murdeshwar HG, Siddiqui S. Papillary carcinoma of breast: minireview. World J. Clin. Cases 4(1), $20-24$ (2016).

38. Fakhreddine $\mathrm{MH}$, Haque W, Ahmed A et al. Prognostic factors, treatment and outcomes in early stage, invasive papillary breast cancer: a SEER investigation of less aggressive treatment in a favorable histology. Am. J. Clin. Oncol. 41(6), 532-537 (2018).

39. Evers K. Significance of finding micropapillary DCIS on core needle biopsy. Acad. Radiol. 18(7), 795-796 (2011).

40. Grabowski J, Salzstein SL, Sadler GR, Blair S. Intracystic papillary carcinoma: a review of 917 cases. Cancer 113(5), 916-920 (2008). 
41. Rakha EA, Varga Z, Elsheik S, Ellis IO. High-grade encapsulated papillary carcinoma of the breast: an under-recognized entity. Histopathology 66(5), 740-746 (2015).

42. Richards S, Li Y, Ioffe OB. Encapsulated and solid papillary carcinoma of the breast: case reports and review of clinicopathologic features. AJSP Rev. Rep. 21(1), 32-36 (2016).

43. Rakha EA, Gandhi N, Climent F et al. Encapsulated papillary carcinoma of the breast: an invasive tumor with excellent prognosis. Am. J. Surg. Pathol. 35(8), 1093-1103 (2011).

44. Jiang T, Tang W, Gu Y, Xu M, Yang W, Peng W. Magnetic resonance imaging features of breast encapsulated papillary carcinoma. J. Comput. Assist. Tomogr. 42(4), 536-541 (2018).

45. Zhang J, Zhang T, Wu N et al. Intracystic papillary carcinoma of the breast: experience of a major Chinese cancer center. Pathol. Res. Pract. 214(4), 579-585 (2018).

46. Farrokh D, Abedi M, Fallah Rastegar Y. An intracystic papillary carcinoma of the breast. Iran J. Cancer Prev. 6(2), 118-121 (2013).

47. George K, Anna Z, Evanthia K, Vassilios K. Encapsulated papillary carcinoma of the breast: an overview. J. Cancer Res. Ther. 9(4), 564-570 (2013).

48. Speer ME, Adrada BE, Arribas EM, Hess KR, Middleton LP, Whitman GJ. Imaging of intracystic papillary carcinoma. Curr. Probl. Diagn. Radiol. 48(4), 348-352 (2019).

49. Guo S, Wang Y, Rohr J et al. Solid papillary carcinoma of the breast: a special entity needs to be distinguished from conventional invasive carcinoma avoiding over-treatment. Breast 26, 67-72 (2016).

50. Saremian J, Rosa M. Solid papillary carcinoma of the breast: a pathologically and clinically distinct breast tumor. Arch. Pathol. Lab. Med. 136(10), 1308-1311 (2012).

51. Clement Z, Jones M. Solid papillary carcinoma of the breast: a review. Int. J. Surg. Med. 3, 1 (2017).

52. Nassar H. Solid papillary carcinoma of the breast. AJSP Rev. Rep. 14(4), 157-161 (2009).

53. You C, Peng W, Shen X, Zhi W, Yang W, Gu Y. Solid papillary carcinoma of the breast: magnetic resonance mammography, digital mammography and ultrasound findings. J. Comput. Assist. Tomogr. 42(5), 771-775 (2018).

54. Zheng Y-Z, Hu X, Shao Z-M. Clinicopathological characteristics and survival outcomes in invasive papillary carcinoma of the breast: a SEER population-based study. Sci. Rep. 6(1), 24037 (2016).

55. Bhosale SJ, Kshirsagar AY, Sulhyan SR, Jagtap SV, Nikam YP. Invasive papillary breast carcinoma. Case Rep. Oncol. 3(3), 410-415 (2010).

56. Chakrabarti R, Batra G. Invasive micropapillary carcinoma breast: a rare entity. Int. Surg. J. 5, 342 (2017).

57. Schneider JA. Invasive papillary breast carcinoma: mammographic and sonographic appearance. Radiology 171(2), 377-379 (1989).

58. Suh YJ, Shin H, Kwon TJ. Natural history of invasive papillary breast carcinoma followed for 10 years: a case report and literature review. Case Rep. Med. 2017, 3725391 (2017).

59. Zheng X, Xia T, Lin L et al. BRAFV600E status and clinical characteristics in solitary and multiple papillary thyroid carcinoma: experience of 512 cases at a clinical center in China. World J. Surg. Oncol. 10, 104 (2012).

60. Luna-More S, Gonzalez B, Acedo C, Rodrigo I, Luna C. Invasive micropapillary carcinoma of the breast. A new special type of invasive mammary carcinoma. Pathol. Res. Pract. 190(7), 668-674 (1994).

61. Jones KN, Guimaraes LS, Reynolds CA, Ghosh K, Degnim AC, Glazebrook KN. Invasive micropapillary carcinoma of the breast: imaging features with clinical and pathologic correlation. AJR Am. J. Roentgenol. 200(3), 689-695 (2013).

62. Yang YL, Liu BB, Zhang X, Fu L. Invasive micropapillary carcinoma of the breast: an update. Arch. Pathol. Lab. Med. 140(8), 799-805 (2016).

63. Liu C, Sidhu R, Ostry A et al. Risk of malignancy in papillary neoplasms of the breast. Breast Cancer Res. Treat. 178(1), 87-94 (2019).

64. Yang Y, Fan Z, Liu Y, He Y, Ouyang T. Is surgical excision necessary in breast papillomas $10 \mathrm{~mm}$ or smaller at core biopsy. Oncol. Res. Treat. 41(1-2), 29-34 (2018).

65. Youk JH, Kim MJ, Son EJ, Kwak JY, Kim EK. US-guided vacuum-assisted percutaneous excision for management of benign papilloma without atypia diagnosed at US-guided 14-gauge core needle biopsy. Ann. Surg. Oncol. 19(3), 922-928 (2012).

66. Wyss P, Varga Z, Rossle M, Rageth CJ. Papillary lesions of the breast: outcomes of 156 patients managed without excisional biopsy. Breast J. 20(4), 394-401 (2014).

67. Armes JE, Galbraith C, Gray J, Taylor K. The outcome of papillary lesions of the breast diagnosed by standard core needle biopsy within a BreastScreen Australia service. Pathology 49(3), 267-270 (2017).

68. Bekes I, Degregorio A, Dewaal A et al. Review on current treatment options for lesions of uncertain malignant potential (B3 lesions) of the breast: do B3 papillary lesions need to be removed in any case by open surgery? Arch. Gynecol. Obstet. 300(2), 481-484 (2019).

69. Rageth CJ, O'flynn EaM, Pinker $\mathrm{K}$ et al. Second International Consensus Conference on lesions of uncertain malignant potential in the breast (B3 lesions). Breast Cancer Res. Treat. 174(2), 279-296 (2019).

-. Pivotal study for management of benign papillary breast lesions. 
70. Rageth CJ, O'flynn EaM, Pinker K et al. Correction to: Second International Consensus Conference on lesions of uncertain malignant potential in the breast (B3 lesions). Breast Cancer Res. Treat. 176(2), 481-482 (2019).

71. Khan S, Diaz A, Archer KJ et al. Papillary lesions of the breast: to excise or observe? Breast J. 24(3), 350-355 (2018).

72. Jung SY, Kang HS, Kwon Y et al. Risk factors for malignancy in benign papillomas of the breast on core needle biopsy. World J. Surg. 34(2), 261-265 (2010).

73. Sakr R, Rouzier R, Salem C et al. Risk of breast cancer associated with papilloma. Eur. J. Surg. Oncol. 34(12), 1304-1308 (2008).

74. Holley SO, Appleton CM, Farria DM et al. Pathologic outcomes of nonmalignant papillary breast lesions diagnosed at imaging-guided core needle biopsy. Radiology 265(2), 379-384 (2012).

75. Ring NY, Diflorio-Alexander RM, Bond JS et al. Papillary and sclerosing lesions of the breast detected and biopsied by MRI: clinical management, upgrade rate and association with apocrine metaplasia. Breast J. 25(3), 393-400 (2019).

76. Heller SL, Elias K, Gupta A, Greenwood HI, Mercado CL, Moy L. Outcome of high-risk lesions at MRI-guided 9-gauge vacuum-assisted breast biopsy. AJR Am. J. Roentgenol. 202(1), 237-245 (2014).

77. Zaleski M, Chen YA, Chetlen AL et al. Should we excise? Are there any clinical or histologic features that predict upgrade in papillomas, incidental or non-incidental? Ann. Diagn. Pathol. 35, 62-68 (2018).

78. Kader $\mathrm{T}$, Elder $\mathrm{K}$, Zethoven $\mathrm{M}$ et al. The genetic architecture of breast papillary lesions as a predictor of progression to carcinoma. NPJ Breast Cancer 6, 9 (2020).

79. Khoury T, Hu Q, Liu S, Wang J. Intracystic papillary carcinoma of breast: interrelationship with in situ and invasive carcinoma and a proposal of pathogenesis: array comparative genomic hybridization study of 14 cases. Mod. Pathol. 27(2), 194-203 (2014).

80. Di Cristofano C, Mrad K, Zavaglia K et al. Papillary lesions of the breast: a molecular progression? Breast Cancer Res. Treat. 90(1), 71-76 (2005).

81. Troxell ML, Levine J, Beadling C et al. High prevalence of PIK3CA/AKT pathway mutations in papillary neoplasms of the breast. Mod. Pathol. 23(1), 27-37 (2010).

82. Mishima C, Kagara N, Ikeda JI et al. Mutational analysis of AKT1 and PIK3CA in intraductal papillomas of the breast with special reference to cellular components. Am. J. Pathol. 188(5), 1106-1112 (2018).

83. Weng Z, Spies N, Zhu SX et al. Cell-lineage heterogeneity and driver mutation recurrence in pre-invasive breast neoplasia. Genome Med. 7(1), 28 (2015).

84. Keppler-Noreuil KM, Sapp JC, Lindhurst MJ et al. Clinical delineation and natural history of the PIK3CA-related overgrowth spectrum. Am. J. Med. Genet. A 164a(7), 1713-1733 (2014). 